\title{
Association of Serum Fibrinogen and Plasma VEGF Levels with Tumor Characteristics and Treatment Response in Operable Breast Carcinoma.
}

Hemant Kumar Khowal

Lady Hardinge Medical College

Raghav Yelamanchi ( $\nabla$ raghavyelamanchi@gmail.com )

Dr Ram Manohar Lohia Hospital and Post Graduate Institute of Medical Education and Research https://orcid.org/0000-0001-6786-8056

NIKHIL GUPTA

Dr Ram Manohar Lohia Hospital and Post Graduate Institute of Medical Education and Research

\section{Binita Goswami}

MAMC: Maulana Azad Medical College

Anju Jain

Lady Hardinge Medical College

Mohinder Pal Arora

Lady Hardinge Medical College

\section{Research Article}

Keywords: Breast carcinoma, Fibrinogen, Vascular endothelial growth factor, Lymph node metastasis, Prognostic mediators in breast carcinoma

Posted Date: June 28th, 2021

DOl: https://doi.org/10.21203/rs.3.rs-260277/v1

License: (a) (1) This work is licensed under a Creative Commons Attribution 4.0 International License. Read Full License 


\section{Abstract \\ Background and Aims:}

A search for factors predicting the behavior of the tumor, its invasiveness, metastasis, response to treatment and prognosis is the primary focus of breast cancer research. The objective of the present study was to study the association of fibrinogen and vascular endothelial growth factor (VEGF) with various parameters of breast carcinoma.

\section{Materials and methods}

A case control was conducted in which fibrinogen and VEGF levels were compared between cases and controls and also with various characteristics of breast carcinoma such as T stage, lymph node positivity, grade, lymphovascular invasion and receptor status. The effect of surgery of breast cancer on fibrinogen and VEGF levels was also studied.

\section{Results}

The levels of fibrinogen and VEGF were significantly higher in cases when compared to controls $(p<$ 0.001). Increased fibrinogen level was significantly associated with higher grade of the tumor, lymph node metastasis and lymphovascular invasion. Increased VEGF level was significantly associated with higher grade and lymphovascular invasion of the tumor. After treatment there was a statistically significant fall in the levels of the above mediators $(p<0.001)$.

\section{Conclusions}

Serum fibrinogen and plasma VEGF levels were significantly higher in patients of breast carcinoma and had significant association with invasiveness of the tumor.

\section{Introduction:}

The incidence of breast cancer is increasing worldwide and at present it is the most common malignancy among woman in India and worldwide [1]. Even though breast cancer is one of the oldest malignancies to be studied, the exact pathogenesis and behavior of different breast cancer subtypes is not adequately known. A search for factors predicting the behavior of the tumor, invasiveness, metastasis, response to treatment and prognosis is the primary focus of breast cancer research at present date. Even though multiple molecular prognostic factors have been discovered, independently the value of these factors is minimal. 
Fibrinogen is a plasma protein that is synthesized by the liver [2]. It plays an important role in the coagulation pathway. It is converted to fibrin by active thrombin. It also acts as an acute phase reactant in tissue injury, inflammation and infection [3]. Malignancy is deemed to be a hypercoagulable state in various studies $[4,5]$. Fibrinogen is hypothesized to play an important role in tumor growth and angiogenesis. Fibrin in the extracellular matrix of the tumors is deposited from the fibrinogen of plasma and not synthesized by the tumor cells. This fibrin matrix will act as a scaffold and harbors many growth and angiogenesis mediators [6]. The role of fibrinogen was also proved in the haematogenous metastasis of tumors in various animal models with fibrinogen deficiency [7]. This has provoked many studies which have investigated the role of fibrinogen in various cancers.

Vascular endothelial growth factor (VEGF) was initially isolated as an endothelial cell mitogen but was later associated with a multitude of signaling processes. The primary function of VEGF is to increase the vascular permeability and angiogenesis in both physiological as well as in pathological states [8]. There are many different types of VEGF. However, VEGF-A is widely studied and is commonly referred to as VEGF. It is secreted by the tumor cells into the micro milieu and acts as a paracrine signaling molecule in addition to its role in vasculogenesis [8]. VEGF plays an important role in tumor stroma formation by stimulating the fibroblasts and also interacts with the tumor lymphocytes. The levels of VEGF were found to be increased in breast cancer in various studies [9-12].

The objective of the present study was to study the association of fibrinogen and VEGF with various parameters of breast carcinoma. Authors have further aimed to study the effect of treatment on the levels of fibrinogen and VEGF. Our hypothesis is that, increased levels of fibrinogen and VEGF are associated with aggressiveness and invasiveness of breast carcinoma which indicate poor prognosis.

\section{Materials And Methods:}

All patients were enrolled in the study after taking written informed consent. The study was conducted after the approval of the Ethics committee of Lady Hardinge Medical College with file no-pgthesis2011.

\subsection{STUDY DESIGN AND POPULATION:}

A case control study was conducted at our institute which is a tertiary care center located in North India. Sample size was 34 cases and controls each. The "case" definition used in our study was female patient of breast carcinoma who presented to our hospital during the study period and satisfying the inclusion and exclusion criteria. Consecutive sampling technique was used to enroll cases in the study. Controls were selected from healthy individuals who visited our hospital for preventive health checkups. Serum levels of fibrinogen and VEGF were compared between cases and controls. The cohort of cases of the case control study was further studied prospectively to study the effect of treatment on the levels of fibrinogen and VEGF.

\subsection{INCLUSION CRITERIA:}


- Cases: Female patients who were diagnosed with non metastatic breast carcinoma who have consented to participate in our study were enrolled.

- Controls: Healthy adult female volunteers who visited the hospital for preventive health checkups and consented to participate in the study were enrolled.

\subsection{EXCLUSION CRITERIA:}

- Cases: Pregnant females were excluded from the study. All metastatic breast carcinoma patients were also excluded. Patients with co-morbidities are excluded as they may interfere with fibrinogen and VEGF values.

- Controls: Individuals with any acute or chronic diseases, disorders of coagulation and present or past history of malignancy were excluded as controls.

\subsection{MANAGEMENT:}

All cases underwent diagnostic procedures such as ultrasound breast, mammography and core needle biopsy of the lesion. Tissue specimens were examined for the following characteristics:

- Histological type of tumor

- Histological grade: Modified Scarff-Bloom-Richardson grading was used and grade1 to 3 were assigned according to differentiation of tumor.

- Mitotic index: 40x objective was used to count mitotic figures and points were given as follows: 1 point- 0 to 5 mitosis per high power field, 2 points- 6 to 10 mitosis per high power field, 3 points- $>11$ mitosis per high power field.

- Estrogen, progesterone and HER-2-neu receptor status: These were ascertained by staining the paraffin sections using monoclonal antibodies to estrogen receptor (ER), progesterone receptor (PR) and HER -2-neu receptor utilizing streptovidin biotin peroxidase method with diaminobenzidine as chromogen after antigen retrieval in citrate buffer at pH 6.0.

Patients with enlarged lymph nodes underwent fine needle aspiration cytology to confirm lymph node metastasis. All cases with symptoms suggestive of systemic metastasis and locally advanced breast carcinoma underwent metastatic workup to rule out metastasis. Blood samples were taken from cases and controls for measurement of fibrinogen and VEGF. All cases later underwent modified radical mastectomy. Two weeks post surgery blood samples were taken from the cases to measure the fibrinogen and VEGF levels.

$5 \mathrm{ml}$ of blood was drawn from the antecubital vein of the patients after applying tourniquet to arm with 24 gauge needle. Venous blood was collected in a plain vial. Blood was centrifuged within 30 minutes and serum and plasma were kept at -80 degree Celsius. Fibrinogen and VEGF levels were quantified later by Enzyme-linked immunosorbent assay (ELISA).

\subsubsection{Fibrinogen measurement:}


Fibrinogen value was calculated by commercially available Human Fibrinogen ELISA kit- AssayMax Human Fibrinogen ELISA Kit (Assaypro, USA, Catalog No. EF1040-1, Lot No. 07251330) which employs a quantitative competitive enzyme immunoassay technique. Murine antibody specific to fibrinogen was pre-coated on to a 96-well microplate. Then standards and specimens were added. This was followed by adding biotinylated fibrinogen and incubation. Then the wells were washed with buffer. Streptavidinperoxidase conjugated antibody was added and the wells were washed to remove unbound antibody. Peroxide enzyme substrate was added for the colour to develop. The colour development was stopped after adding acidic stop solution and the intensity of colour was measured. Normal assay range by this test was $2.0-3.5 \mathrm{mg} / \mathrm{ml}$.

\subsubsection{VEGF measurement:}

VEGF value was calculated by commercially available Human VEGF ELISA kit- EIA- 4819/96 (DRG Instruments $\mathrm{GmbH}$,Germany) which employs enzyme immunoassay for the quantitative determination of human VEGF. Murine antibody specific to fibrinogen was pre-coated on to a 96 -well microplate. Then standards and specimens were added. This assay employs an antibody specific for human VEGF coated onto 96-well microplate. Biotinylated anti-human VEGF was added later. After washing away unbound biotinylated antibody, horse radish peroxidase-conjugated streptavidin was added to the wells. The wells were again washed. Following this, substrate solution was added to the wells. The colour development was stopped after adding acidic stop solution and the intensity of colour was measured. Normal assay range by this test was approximately $700 \mathrm{pg} / \mathrm{ml}$.

\subsection{STATISTICAL ANALYSIS:}

The sample size was 34 patients and 34 controls calculated with a margin of error of $5 \%$. The data acquired was coded and recorded in the MS Excel spreadsheet (Microsoft Office, Microsoft, Washington). Data was analyzed using Statistical Package for Social Sciences (SPSS) version 17.0 (IBM SPSS Statistics, International Business Machines Corporation, New York). Data was normally distributed. Normally distributed continuous variables were compared using the unpaired $t$ test for two groups and ANOVA for three or more groups. Categorical variables were analyzed using either the chi square test or Fisher's exact test as appropriate. For all statistical tests, a p value of less than 0.05 was considered significant.

\section{Results:}

The age distribution of cases was in the range of 25 to 80 years. Most of the patients belonged to the age group of 41 to 50 years (35.3\%) and the mean age of cases was 48.4713 .70 [Table1]. The distribution of cases as per the TNM classification is depicted in Table2. Cases and controls were matched with respect to age as the difference between the mean age of cases and controls was not significant [Table1]. The pre treatment serum level of fibrinogen was found to be raised in cases with mean \pm standard deviation (SD) value of $13.83 \pm 3.83 \mathrm{mg} / \mathrm{ml}$ as compared to controls with a mean $\pm S D$ value of $2.47 \pm 4.5 \mathrm{mg} / \mathrm{ml}$. The results were statistically significant [Table1].The pre treatment plasma level of VEGF was also found to 
be raised in cases with a mean $\pm S D$ value of $1392.06 \pm 422.72 \mathrm{pg} / \mathrm{ml}$ as compared with controls with a mean $\pm S D$ value $840.89 \pm 32.73 \mathrm{pg} / \mathrm{ml}$. These results were found to be statistically significant [Table1].

Table 1

Table comparing age, fibrinogen and VEGF levels between cases and controls

\begin{tabular}{|llll|}
\hline & Controls & Cases & P value \\
\cline { 2 - 4 } & Mean \pm SD & Mean \pm SD & \\
\hline Age (years) & $49.74 \pm 14.69$ & $48.47 \pm 13.70$ & 0.711 \\
\hline Fibrinogen(S1) mg/ml & $2.47 \pm 0.45$ & $13.83 \pm 3.83$ & $<0.001^{*}$ \\
\hline VEGF(P1) pg/ml & $840.89 \pm 32.73$ & $1392.06 \pm 422.72$ & $<0.001^{*}$ \\
\hline * significant; SD: Standard deviation; VEGF :vascular endothelial growth factor; \\
\hline
\end{tabular}

Table 2

Table showing the distribution of breast carcinoma cases as per TNM staging

\begin{tabular}{|lll|}
\hline TNM Stage & Frequency & Proportion \\
\hline T1N0M0 & 3 & $8.8 \%$ \\
\hline T2N0M0 & 12 & $35.3 \%$ \\
\hline T3N0M0 & 6 & $17.6 \%$ \\
\hline T4N1M0 & 1 & $2.9 \%$ \\
\hline T4aN1M0 & 3 & $8.8 \%$ \\
\hline T4bN1M0 & 8 & $23.5 \%$ \\
\hline T4cN1M0 & 1 & $2.9 \%$ \\
\hline Total & 34 & $100 \%$ \\
\hline
\end{tabular}

Out of the 34 cases, 33 cases were diagnosed with invasive ductal carcinoma and one patient was diagnosed with invasive lobular carcinoma. The mean values of serum fibrinogen and plasma VEGF for various $T$ stages of the tumor were compared and were found not be significant [Tables 3 and 4]. In our study, out of 34 cases 12 cases (35.3\%) were found to have positive lymph nodes. The serum fibrinogen values were found to be higher in cases with positive lymph nodes with a mean value \pm SD of $16.13 \pm$ $2.61 \mathrm{mg} / \mathrm{dl}$ as compared to mean value \pm SD of $12.58 \pm 3.85 \mathrm{mg} / \mathrm{dl}$ in cases with no positive lymph nodes and the difference was statistically significant [Table 3]. The serum VEGF values were found to be higher in cases with positive lymph nodes with a mean value \pm SD of $1560.00 \pm 457.07 \mathrm{pg} / \mathrm{ml}$ as compared to mean value \pm SD of $1300.45 \pm 382.70 \mathrm{pg} / \mathrm{ml}$ in cases with no positive lymph nodes. However, the difference was not statistically significant [Table 4]. 
Table 3

Table showing the association between Fibrinogen and parameters

\begin{tabular}{|c|c|c|c|c|}
\hline \multirow[t]{2}{*}{ PARAMETER } & & \multirow[t]{2}{*}{ FREQUENCY } & FIBRINOGEN (mg/dl) & \multirow[t]{2}{*}{ P-VALUE } \\
\hline & & & Mean \pm SD & \\
\hline \multirow[t]{4}{*}{ T STAGE } & T 1 & 3 & $10.53 \pm 4.20$ & \multirow[t]{4}{*}{0.354} \\
\hline & T 2 & 12 & $13.60 \pm 3.84$ & \\
\hline & T 3 & 7 & $13.60 \pm 5.38$ & \\
\hline & T 4 & 12 & $14.92 \pm 2.80$ & \\
\hline \multirow[t]{2}{*}{ LYMPH NODE METASTASIS } & Present & 12 & $16.13 \pm 2.61$ & \multirow[t]{2}{*}{$0.008^{*}$} \\
\hline & Absent & 22 & $12.58 \pm 3.85$ & \\
\hline \multirow[t]{3}{*}{ GRADE } & Grade 1 & 10 & $11.86 \pm 4.83$ & \multirow[t]{3}{*}{$0.011^{*}$} \\
\hline & Grade 2 & 12 & $12.98 \pm 2.92$ & \\
\hline & Grade 3 & 12 & $16.33 \pm 2.30$ & \\
\hline \multirow[t]{3}{*}{ MITOTIC INDEX } & Score 1 & 12 & $12.12 \pm 4.42$ & \multirow[t]{3}{*}{0.152} \\
\hline & Score 2 & 15 & $14.65 \pm 3.65$ & \\
\hline & Score 3 & 7 & $15.03 \pm 2.17$ & \\
\hline \multirow[t]{2}{*}{ LYMPHOVASCULAR INVASION } & Present & 20 & $15.24 \pm 3.09$ & \multirow[t]{2}{*}{$0.008^{*}$} \\
\hline & Absent & 14 & $11.83 \pm 4.00$ & \\
\hline \multirow[t]{2}{*}{ ESTROGEN RECEPTOR } & Positive & 4 & $13.13 \pm 3.74$ & \multirow[t]{2}{*}{0.465} \\
\hline & Negative & 30 & $14.17 \pm 3.91$ & \\
\hline \multirow[t]{2}{*}{ PROGESTERONE RECEPTOR } & Positive & 10 & $12.56 \pm 3.40$ & \multirow[t]{2}{*}{0.216} \\
\hline & Negative & 24 & $14.37 \pm 3.94$ & \\
\hline \multirow[t]{2}{*}{ HER-2-NEU } & Positive & 12 & $14.48 \pm 2.81$ & \multirow[t]{2}{*}{0.475} \\
\hline & Negative & 22 & $13.48 \pm 4.31$ & \\
\hline
\end{tabular}


Table 4

Table showing the association between VEGF and parameters

\begin{tabular}{|c|c|c|c|c|}
\hline \multirow[t]{2}{*}{ PARAMETER } & & \multirow[t]{2}{*}{ FREQUENCY } & VEGF(pg/ml) & \multirow[t]{2}{*}{ P-VALUE } \\
\hline & & & Mean \pm SD & \\
\hline \multirow[t]{4}{*}{ T STAGE } & T 1 & 3 & $1350.00 \pm 266.67$ & \multirow[t]{4}{*}{0.273} \\
\hline & T 2 & 12 & $1224.17 \pm 367.83$ & \\
\hline & T 3 & 7 & $1386.67 \pm 536.05$ & \\
\hline & T 4 & 12 & $1559.23 \pm 420.60$ & \\
\hline \multirow[t]{2}{*}{ LYMPH NODE METASTASIS } & Present & 12 & $1560.00 \pm 457.07$ & \multirow[t]{2}{*}{0.087} \\
\hline & Absent & 22 & $1300.45 \pm 382.70$ & \\
\hline \multirow[t]{3}{*}{ GRADE } & Grade 1 & 10 & $1139.00 \pm 372.93$ & \multirow[t]{3}{*}{$0.025^{*}$} \\
\hline & Grade 2 & 12 & $1378.33 \pm 362.79$ & \\
\hline & Grade 3 & 12 & $1616.67 \pm 420.96$ & \\
\hline \multirow[t]{3}{*}{ MITOTIC INDEX } & Score 1 & 12 & $1196.67 \pm 366.51$ & \multirow[t]{3}{*}{0.131} \\
\hline & Score 2 & 15 & $1518.00 \pm 495.94$ & \\
\hline & Score 3 & 7 & $1457.14 \pm 204.10$ & \\
\hline \multirow[t]{2}{*}{ LYMPHOVASCULAR INVASION } & Present & 20 & $1560.50 \pm 367.76$ & \multirow[t]{2}{*}{$0.003^{*}$} \\
\hline & Absent & 14 & $1148.57 \pm 383.90$ & \\
\hline \multirow[t]{2}{*}{ ESTROGEN RECEPTOR } & Positive & 4 & $1299.09 \pm 388.96$ & \multirow[t]{2}{*}{0.383} \\
\hline & Negative & 30 & $1436.52 \pm 439.18$ & \\
\hline \multirow[t]{2}{*}{ PROGESTERONE RECEPTOR } & Positive & 10 & $1261.00 \pm 387.77$ & \multirow[t]{2}{*}{0.249} \\
\hline & Negative & 24 & $1446.67 \pm 432.39$ & \\
\hline \multirow[t]{2}{*}{ HER-2-NEU } & Positive & 12 & $1465.00 \pm 526.37$ & \multirow[t]{2}{*}{0.466} \\
\hline & Negative & 22 & $1352.27 \pm 361.90$ & \\
\hline
\end{tabular}

The mean values of fibrinogen and VEGF were higher in cases with higher grade of tumor [Tables 3 and 4]. The difference was found to be statistically significant. The mean values of fibrinogen and VEGF were higher in cases with higher mitotic index [Tables 3 and 4]. However, the difference was not found to be statistically significant. The serum fibrinogen level was found to be more in patients with vascular invasion with a mean value \pm SD of $15.24 \pm 3.09 \mathrm{mg} / \mathrm{ml}$ as compared to a mean value \pm SD of $11.83 \pm$ $4.00 \mathrm{mg} / \mathrm{ml}$ in patients without vascular invasion. The difference was statistically significant [Table 3]. 
The plasma VEGF level was found to be more in patients with vascular invasion with a mean value \pm SD of $1560.50 \pm 367 \mathrm{pg} / \mathrm{ml}$ as compared to a mean value \pm SD of $1148.57 \pm 383.90 \mathrm{pg} / \mathrm{ml}$ in patients without vascular invasion. The difference was found to be statistically significant [Table 4].

In our study the serum fibrinogen level was found to be less with a mean value \pm SD of $13.13 \pm 3.74$ $\mathrm{mg} / \mathrm{ml}$ in ER positive cases as compared to a mean value \pm SD of $14.17 \pm 3.91 \mathrm{mg} / \mathrm{ml}$ in ER negative cases. The difference was not statistically significant [Table 3]. The plasma VEGF level was also less with a mean value \pm SD of $1299.09 \pm 388.96 \mathrm{pg} / \mathrm{ml}$ in ER positive cases as compared to a mean value \pm SD of $1436.52 \pm 439.18 \mathrm{pg} / \mathrm{ml}$ in ER negative cases. The difference was not statistically significant [Table 4].

The serum fibrinogen level was found to be less with a mean value \pm SD of $12.56 \pm 3.40 \mathrm{mg} / \mathrm{ml}$ in PR positive cases as compared to a mean value \pm SD of $14.37 \pm 3.94 \mathrm{mg} / \mathrm{ml}$ in PR negative cases. The difference was not statistically significant [Table 3]. The plasma VEGF level was also less with a mean value \pm SD of $1261.00 \pm 387.77 \mathrm{pg} / \mathrm{ml}$ in PR positive cases as compared to a mean value \pm SD of $1446.67 \pm 432.39 \mathrm{pg} / \mathrm{ml}$ in PR negative cases. The difference was not statistically significant [Table 4].

The serum fibrinogen level was found to be raised with a mean value \pm SD of $14.48 \pm 2.81 \mathrm{mg} / \mathrm{ml}$ in HER2-neu positive cases as compared to a mean value \pm SD of $13.48 \pm 4.31 \mathrm{mg} / \mathrm{ml}$ in HER-2-neu negative cases. The difference was not statistically significant [Table 3]. The plasma VEGF level was also raised with a mean value \pm SD of $1465.00 \pm 526.37 \mathrm{pg} / \mathrm{ml}$ in HER-2-neu positive cases as compared to a mean value \pm SD of $1352.27 \pm 361.90 \mathrm{pg} / \mathrm{ml}$ in HER-2-neu negative cases. The difference was not statistically significant [Table 4].

In case of fibrinogen, after MRM values decreased from pre treatment mean value \pm SD of $13.85 \pm 4.19$ $\mathrm{mg} / \mathrm{ml}$ to post treatment mean value \pm SD of $6.21 \pm 3.11 \mathrm{mg} / \mathrm{ml}$ which was found to be significant [Table 5]. In case of VEGF, after MRM values decreased from pre treatment mean value \pm SD of $1393.21 \pm$ $458.83 \mathrm{pg} / \mathrm{ml}$ to post treatment mean value \pm SD of $891 \pm 330.89 \mathrm{pg} / \mathrm{ml}$ which was found to be significant [Table 5].

Table 5

Table comparing pre and post treatment fibrinogen and VEGF levels

\section{MRM}

Pre

Post

P value

Mean \pm SD

Mean \pm SD

Fibrinogen

$13.85 \pm 4.19$

$6.21 \pm 3.11$

$<0.001^{*}$

$(\mathrm{mg} / \mathrm{ml})$

VEGF (pg/ml)

$1393.21 \pm 458.83$

$891.43 \pm 330.89$

$<0.001^{*}$

* significant; MRM: Modified radical mastectomy; SD: Standard deviation; VEGF :vascular endothelial growth factor; 


\section{Discussion:}

Apart from interacting with the host human system, tumor cells also interact with other host physiological pathways such as the platelet and coagulation pathways $[13,14]$. Tumor growth and hypoxia induce release of tissue factor [15]. Tissue factor activates the extrinsic pathway of coagulation to form the prothrombinase complex. The prothrombinase complex cleaves the inactive prothrombin to thrombin which in turn activates platelets and fibrinogen. The activated fibrinogen is converted to fibrin which forms a matrix for the activated platelets and growth factors. Thrombin also activates protease activated receptor 1(PAR 1) peptide, which in turn activates growth related oncogene alfa (GRO-a). Thrombin, PAR 1 peptide and GRO-a will cause release of matrix metallo proteinases and growth factors like VEGF which help in tumor cell growth, invasion and metastasis [16-18]. The present study was conducted to study the effect of two important mediators of the above pathways fibrinogen and VEGF in breast cancer.

Most of the patients in our study belonged to the age group of 41-50 years. In the present study the mean fibrinogen level was elevated in breast cancer patients when compared to controls as in previous studies. The levels of fibrinogen in our study had good association with grade of the tumor, lymph node metastasis and lymphovascular invasion. In a study by Wen $\mathrm{J}$ et al and Shu YJ et al, fibrinogen levels were associated with lymph node metastasis as well as tumor size $[19,20]$. However, no such association with tumor size was found in our study. There was also no association of fibrinogen with ER, PR and HER-2-neu receptor status in our study as in other studies [19].

Serum fibrinogen level in malignancy is hypothesized to be mediated by interleukin- 6 secondary to the inflammatory reaction to the tumor and hypercoagulable state [19]. The elevated fibrinogen level is said to facilitate the survival and migration of tumor cells in the blood. Shu YJ et al demonstrated that fibrinogen also causes epithelial mesenchymal transition by up regulating vimentin and decreasing the expression of E-cadherin of tumor cells resulting in invasiveness of the tumor [20].

The mean level of VEGF was higher in patients when compared to controls in our study which was found to be significant. This finding was consistent with findings in other previous studies [10-12]. The plasma level of VEGF in the present study was associated only with grade and lymphovascular invasion of the tumor. However, there was no association with other parameters like tumor size, lymph node metastasis, ER, PR and HER-2-neu receptor status as in previous studies [21].

Post treatment, the levels of serum fibrinogen and plasma VEGF values in patients decreased in our study, which was statistically significant. This shows that the levels of these two molecules are driven by the tumor load. In various studies elevated levels of fibrinogen and VEGF were associated with poor overall survival indicating the role of these molecules in determining negative prognosis $[19,22]$. Drug trials studying the role of anticoagulants in breast cancer had conflicting results regarding outcomes [23-25]. Many of these studies enrolled patients with advanced diseases. Studies regarding the role of anti-VEGF in breast cancer have shown only modest results [26]. 
The limitation of the present study was small sample size. Other mediators such as thrombin, interleukin6 , platelet count, etc were not considered in this study. Patient population was limited to only non metastatic breast carcinoma patients. There was no long term follow up in this study to investigate the role of these factors in overall and disease free survival.

\section{Conclusions:}

Serum fibrinogen and plasma VEGF levels were significantly higher in patients of carcinoma breast when compared to controls. Serum fibrinogen level was significantly associated with grade of the tumor, lymph node metastasis and lymphovascular invasion. Plasma VEGF level was associated with grade and lymphovascular invasion of the tumor. Post treatment there was a statistically significant fall in the levels of the above mediators. Further studies on larger sample size are required to generalize the results of this study. The role of these mediators if adequately proved could act pave way for newer drugs in the treatment of breast carcinoma.

\section{Declarations}

Contributions: HKK conceptualized the study and conducted it. RY designed the methodology and wrote the manuscript. NG helped in data acquisition and reviewed the manuscript. BG conducted the study and was in charge of the biochemical tests conducted. AJ conducted the study and helped in data acquisition. MPA conducted the study and supervised it.

Funding: No sources of funding for this study

Conflict of Interest: Authors declare that they have no conflict of interest.

Consent to participate: Witten informed consent for participation was taken from all the participants.

Consent for publication: Consent for publication has been taken for publication of results and data from all the participants.

Ethical approval: This study was performed in line with the principles of the Declaration of Helsinki 1964 revised in 2013. Approval was granted by the Ethics Committee of Lady Hardinge Medical College with file no-pgthesis2011.

\section{References}

1. Rangarajan B, Shet T, Wadasadawala T, Nair NS, Sairam RM, Hingmire SS, et al. Breast cancer: An overview of published Indian data. South Asian J Cancer. 2016;5(3):86-92. doi:10.4103/2278330X.187561.

2. Tennent GA, Brennan SO, Stangou AJ, O'Grady J, Hawkins PN, Pepys MB. Human plasma fibrinogen is synthesized in the liver. Blood. 2007;109(5):1971-4. doi:10.1182/blood-2006-08-040956. 
3. Mosesson MW. Fibrinogen and fibrin structure and functions. J Thromb Haemost. 2005;3(8):1894904. doi:10.1111/j.1538-7836.2005.01365.x.

4. Lip GY, Chin BS, Blann AD. Cancer and the prothrombotic state. Lancet Oncol. 2002;3(1):27-34. doi:10.1016/s1470-2045(01)00619-2.

5. Goldenberg N, Kahn SR, Solymoss S. Markers of coagulation and angiogenesis in cancer-associated venous thromboembolism. J Clin Oncol. 2003;21(22):4194-9. doi:10.1200/JC0.2003.05.165.

6. Simpson-Haidaris PJ, Rybarczyk B. Tumors and fibrinogen. The role of fibrinogen as an extracellular matrix protein. Ann N Y Acad Sci. 2001;936:406-25.

7. Palumbo JS, Kombrinck KW, Drew AF, et al. Fibrinogen is an important determinant of the metastatic potential of circulating tumor cells. Blood. 2000;96(10):3302-9.

8. Goel HL, Mercurio AM. VEGF targets the tumour cell. Nat Rev Cancer. 2013 Dec;13(12):871-82. doi:10.1038/nrc3627.

9. Reeves KW, Ness RB, Stone RA, Weissfeld JL, Vogel VG, Powers RW, Modugno F, Cauley JA. Vascular endothelial growth factor and breast cancer risk. Cancer Causes Control. 2009;20(3):375-86. doi:10.1007/s10552-008-9252-4.

10. Benoy I, Salgado R, Colpaert C, Weytjens R, Vermeulen PB, Dirix LY. Serum interleukin 6, plasma VEGF, serum VEGF, and VEGF platelet load in breast cancer patients. Clin Breast Cancer. 2002;2(4):311-5. doi:10.3816/cbc.2002.n.008.

11. Coşkun U, Günel N, Sancak B, et al. Significance of serum vascular endothelial growth factor, insulinlike growth factor-I levels and nitric oxide activity in breast cancer patients. Breast. 2003;12(2):10410. doi:10.1016/s0960-9776(02)00214-x.

12. Hoar FJ, Lip GY, Belgore F, Stonelake PS. Circulating levels of VEGF-A, VEGF-D and soluble VEGF-A receptor (sFlt-1) in human breast cancer. Int J Biol Markers. 2004;19(3):229-35.

13. Khangarot SS, Gupta N, Goswami B, et al. Correlation of D dimer and factor VIII levels with histopathology in patients with breast carcinoma. Cancer Biomark. 2010;7(6):305-14. doi:10.3233/CBM-2010-0196.

14. Goswami B, Rajappa M, Gupta N, et al. Breast Cancer: Interaction Between Oxidant-antioxidant Dynamics and Inflammation in Indian Females. Cancer Biomarkers. 2010;6(2):95-103.

15. Rydén L, Grabau D, Schaffner F, Jönsson PE, Ruf W, Belting M. Evidence for tissue factor phosphorylation and its correlation with protease-activated receptor expression and the prognosis of primary breast cancer. Int J Cancer. 2010;126(10):2330-40. doi:10.1002/ijc.24921.

16. Nierodzik ML, Karpatkin S. Thrombin induces tumor growth, metastasis, and angiogenesis: Evidence for a thrombin-regulated dormant tumor phenotype. Cancer Cell. 2006;10(5):355-62. doi:10.1016/j.ccr.2006.10.002.

17. Caunt M, Hu L, Tang T, Brooks PC, Ibrahim S, Karpatkin S. Growth-regulated oncogene is pivotal in thrombin-induced angiogenesis. Cancer Res. 2006;66(8):4125-32. doi:10.1158/0008-5472.CAN-052570 . 
18. Lal I, Dittus K, Holmes CE. Platelets, coagulation and fibrinolysis in breast cancer progression. Breast Cancer Res. 2013;15(4):207. doi:10.1186/bcr3425.

19. Mei Y, Zhao S, Lu X, Liu H, Li X, Ma R. Clinical and Prognostic Significance of Preoperative Plasma Fibrinogen Levels in Patients with Operable Breast Cancer. PLoS One. 2016;11(1):e0146233. doi:10.1371/journal.pone.0146233.

20. Shu YJ, Weng H, Bao RF, et al. Clinical and prognostic significance of preoperative plasma hyperfibrinogenemia in gallbladder cancer patients following surgical resection: a retrospective and in vitro study. BMC Cancer. 2014;14:566.

21. Granato AM, Nanni O, Falcini F, Folli S, Mosconi G, De Paola F, et al. Basic fibroblast growth factor and vascular endothelial growth factor serum levels in breast cancer patients and healthy women: useful as diagnostic tools? Breast Cancer Res. 2004;6(1):R38-45. doi:10.1186/bcr745.

22. Gasparini G. Prognostic value of vascular endothelial growth factor in breast cancer. Oncologist. 2000;5(Suppl 1):37-44. doi:10.1634/theoncologist.5-suppl_1-37.

23. Sideras K, Schaefer PL, Okuno SH, et al. Low-molecular-weight heparin in patients with advanced cancer: a phase 3 clinical trial. Mayo Clin Proc. 2006;81(6):758-767. doi:10.4065/81.6.758.

24. Klerk CP, Smorenburg SM, Otten HM, et al. The effect of low molecular weight heparin on survival in patients with advanced malignancy. J Clin Oncol. 2005;23(10):2130-5. doi:10.1200/JC0.2005.03.134.

25. Agnelli G, Gussoni G, Bianchini C, et al. Nadroparin for the prevention of thromboembolic events in ambulatory patients with metastatic or locally advanced solid cancer receiving chemotherapy: a randomised, placebo-controlled, double-blind study. Lancet Oncol. 2009;10(10):943-9. doi:10.1016/S1470-2045(09)70232-3.

26. Kristensen TB, Knutsson ML, Wehland M, Laursen BE, Grimm D, Warnke E, et al. Anti-vascular endothelial growth factor therapy in breast cancer. Int J Mol Sci. 2014;15(12):23024-41. doi:10.3390/ijms151223024. 